\title{
Effects of Horizontal Beam Angulations and Imaging System on the Identification of the MB2 of Maxillary First Molar: An ROC Analysis
}

\author{
Ibtesam Orafi ${ }^{1, *}$, Mohammad Hammad $^{2}$ \\ ${ }^{1}$ School of Dentistry, University of Benghazi, Libya \\ ${ }^{2}$ School of Dentistry, University of Jordan, Jordan
}

Copyright $\bigcirc 2017$ by authors, all rights reserved. Authors agree that this article remains permanently open access under the terms of the Creative Commons Attribution License 4.0 International License

\begin{abstract}
The aim of this study was to evaluate the optimal horizontal beam angulation for the detection of second mesiobuccal canal (MB2) in maxillary first molar using three imaging modalities in terms of receiver operating characteristic (ROC) curve. Micro-computed tomography (micro-CT) was used to validate the presence or absence of MB2 canal. Images were generated with three different imaging modalities (analogue film, Visualix and VistaScan) for the twelve models at $10^{\circ}$ intervals between $0^{\circ}$ to $30^{\circ}$ from both right and left sides. Each model consisted of maxillary second premolar, maxillary first and second molar arranged to replicate a posterior dentate maxilla. Images were scored on a 5-point scale by 15 observers. ROC analysis was performed to identify the optimal horizontal angulation for the three imaging modalities and the best observer groups. ANOVA was also used to assess if there was a difference between the three imagining modalities and between the observer groups. ROC analysis demonstrated that the highest area under the curve (AUC) was related to angle $+20^{\circ}$ (right). The AUC for the three radiographic techniques at angle $+20^{\circ}$ were as followed (analogue film, 0.625; Visualix, 0.544; VistaScan, 0.508). There was a significant difference between the analogue film and the other two digital systems $(p<0.05)$. The $+20^{\circ}$ horizontal beam angulation for the analogue film was found to be optimal in the identification of MB2 canal with all imaging modalities. Endodontists demonstrated a significantly better performance compared with the other two groups.
\end{abstract}

Keywords Radiography, MB2, Micro-CT, ROC

\section{Introduction}

One of the contributing factors to a successful root canal therapy is the identification of all root canals enabling each to be cleaned, shaped and obturated [1-3]. The maxillary first molar often exhibits complex anatomy due to the presence of MB2 canals whose frequency can vary from $18.6 \%$ [4] to $96 \%$ [5]. Previous studies conducted in this field have been reliant on destructive techniques, such as clearing and sectioning to identify the presence of MB2 canal. However, the introduction of micro-CT has supplanted these techniques by providing a 3D analysis of root anatomy [6-8]. Within clinical practice, conventional radiography provides the clinician with a two dimensional image. As such, information highlighting the presence of the MB2 may be overlooked or become obscured on the resultant image due to image geometry [9]. As such, current clinical opinion supports the routine use of parallax to identify the presence or absence of MB2 [2].

The literature reveals a limited number of in vitro studies, which have compared the effectiveness of conventional and digital radiography when detecting the MB2 canal [9-11]. However, none of the latter studies have used ROC analysis to determine the presence or absence of MB2. The aim of this in vitro study was to determine the optimal horizontal beam angulation for the detection of the MB2 canal in the maxillary first molar using three imaging modalities: analogue film, Visualix ${ }^{\circledR}$ and VistaScan ${ }^{\circledR}$ digital systems using observers with different levels of clinical experience. It also aimed to ascertain whether or not there was a significant difference between either of the three imaging systems and observer groups in the detection of MB2 canal in the maxillary first molar.

\section{Materials and Methods}

A SkyScan 1072 (SkyScan, Kontich, Belgium) high-resolution micro-CT scanner was used to scan the thirty-one extracted maxillary first permanent molars. Adjustments were made to maximise the optimal parameters for image acquisition and reconstruction. Following this, each tooth was positioned on the specimen stage and scanned 
using a pixel size of $19.1 \mu \mathrm{m}$, rotational step of $0.45^{\circ}$, rotational angle of $180^{\circ}$ and a 3.1 second exposure time. Using NRecon software (SkyScan), images were reconstructed to produce two-dimensional slices of the roots. Out of 31 teeth a 12 teeth were selected (six with MB1 canal and six with MB2 canal).

An experimental jig was manufactured to ensure constant focus-to-object distance and optimal exposure levels were applied [12]. Twelve models were prepared consisting of a group of three teeth (maxillary second premolar and first and second permanent molars) to simulate the natural arch form in the posterior maxilla. The latter were embedded in beading wax (Kemdent, Associated Dental Products Ltd, Wiltshire, UK). The teeth were firmly secured in the model tray using sticky wax (Whip Mix Corporation, Louisville, $\mathrm{Ky}, \mathrm{USA}$ ) and cyanoacrylate adhesive (Rocket, DVA Inc., Corona, Calif, USA) being retained by a rigid upper arch stock impression tray (Polytray, Dentsply Ltd., De Trey, UK). To simulate the clinical scenario, a $2.5 \mathrm{~cm}$ plexiglass was placed between the teeth set up and the cone beam (Fig. $1)$.

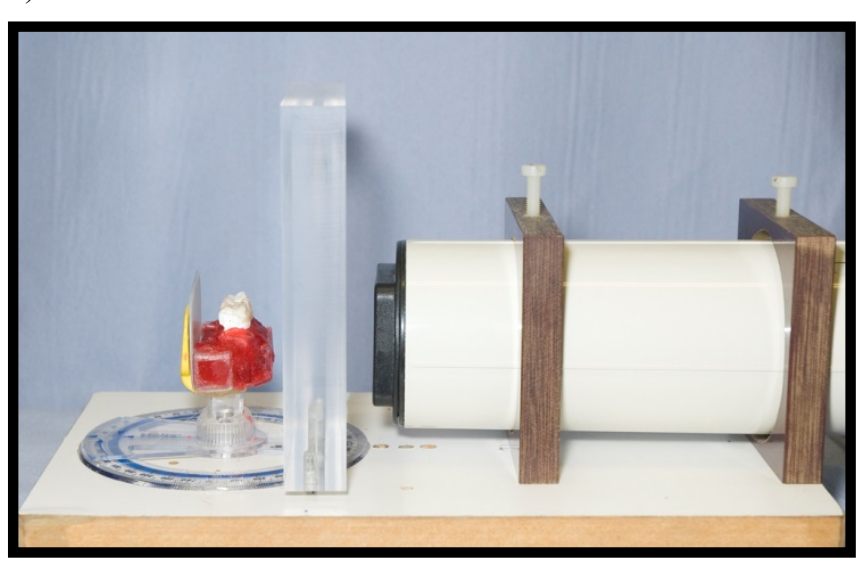

Figure 1. An example of the illustration of experimental set used

Prior to the commencement of the study, a number of analogue films were exposed using a range of different exposure values. A pilot study was conducted to choose the best exposure time. Different exposures were tested $(0.12 \mathrm{~s}$; $0.16 \mathrm{~s} ; 0.20 \mathrm{~s} ; 0.25 \mathrm{~s}, 0.32 \mathrm{~s}, 0.40)$. The quality of the images was determined subjectively.

A $30 \mathrm{~cm}$ beam aiming device fitted with a rectangular collimator was used to ensure standardisation of the focusto-object distance. The study used size $2 \mathrm{~F}$-speed analogue film (Kodak, Hemel Hempstead, UK) supported by a Rinn $\mathrm{XCP}^{\circledR}$ posterior film holder (Dentsply, Elgin, Illinois). All films were developed using the same automatic processor (Dürr GmbH, Bietigheim-Bissingen, Germany) employing fresh chemistry routinely monitored by densitometric analysis to ensure standardised processing. The resultant films were subsequently viewed independently by two specialists in Dental and Maxillofacial Radiology under ideal viewing conditions which consisted of viewing the resultant images in a room with ambient lighting and with the use of a light box with a $30 \mathrm{~cm} \times 15 \mathrm{~cm}$ viewing area (Rinn Dentsply
Ltd., Weybridge, UK). The light box had been fitted with a new bulb and the viewing surface was cleaned prior to the session and each film was mounted within an opaque mask. Consensus between the two specialists allowed the establishment of an optimum radiographic exposure value of 0.25 seconds.

For digital imaging, the study employed a CCD system (Visualix USB: Dentsply, Gendex Dental Systems, Milan, Italy) with Vixwin 2000 software, version 1.4 (Dentsply, Gendex Dental Systems) and a phosphor plate system (VistaScan-Perio, Dürr Dental, Bietigheim-Bissingen, Germany) with Dbswin version 4.5 software (Dürr Dental, Bietigheim-Bissingen, Germany). Both sensors approximated to a size 2 conventional film. For all exposures the focus to object distance was maintained at $32 \mathrm{~cm}$ to ensure a constant magnification factor.

For each of the digital sensors, the manufacturers' optimal exposure values were employed. Consequently, all the images obtained by using the three imaging modalities were of optimal quality to allow the observer to identify anatomical structures within the image including the presence or absence of the MB2 canal. The image viewed by the participating clinicians was one which displayed optimised density and contrast.

The beam alignment device (Rinn Corporation, Elgin, Illinois, USA) was modified to incorporate a protractor which was used to vary accurately the horizontal angulation of the x-ray beam from $0^{\circ}$ to $\pm 30^{\circ}$ at $10^{\circ}$ intervals ${ }^{12}$. A total of seven angulations $\left(+10^{\circ},+20^{\circ},+30^{\circ}, 0^{\circ},-10^{\circ},-20^{\circ},-30^{\circ}\right)$ were obtained from each model.

The viewing session for analogue images was carried out as previously described. Each of the CCD and PSP images were viewed directly from the same flat LCD monitor screen (Samsung SyncMaster 171s) on two occasions. Prior to each imaging session, the monitor screen was cleaned with a proprietary anti-static cloth (AF Screen-Clene Duo). The observers viewed the images in a room with subdued lighting. Each image was identified only by a letter (A to $G$ ) and a period of three-weeks was allowed between interpretation sessions to ensure participants had no recollection of their previous assessments. A total of 84 images were evaluated by observers. The latter were recruited from different clinical backgrounds (five endodontists, five GDPs and five postgraduates). Each participant rated the presence or absence of MB2 on a five-point scale from 'definitely not present' (1), 'probably not present' (2), '50/50' (3), 'probably present' (4), to 'definitely present' (5). For the digital images, the observers were instructed not to alter the contrast or brightness of the monitor ensuring that the viewing conditions remained constant for all participants. No time restriction was given during the interpretation sessions. Using SPSS 15.0 for windows software (SPSS Inc, Chicago, IL), data was analysed by the ROC with a 3.5 cut-off point. An ANOVA test with a Bonferroni post-hoc correction was also used to evaluate the difference between observer groups and the imaging modalities. The $95 \%$ confidence interval 
was being set as the threshold for statistical significance.

\section{Results}

The AUC for analogue film, Visualix and VistaScan ranged between $0.487-0.625,0.440-0.544$ and $0.446-0.508$ respectively. Using an angle of $+20^{\circ}$, the highest AUC (0.625) was recorded using analogue film, and the lowest AUC related to Vista Scan (0.508) (Fig. 2).

One way ANOVA was used to assess if there was a significant difference between all imaging modalities in relation to the adoption of a $+20^{\circ}$ angulation of the $\mathrm{x}$-ray beam. The latter recorded a significant difference between all imaging modalities $(p<0.05)$. The Bonferroni post-hoc test showed a significant difference between analogue film and Visualix $(p=0.03)$ and between analogue film and the VistaScan $(p=0.04)$. However, there was no significant difference between the Visualix and VistaScan $(p=0.99)$ (Table 1).

The AUC for all observers at $+20^{\circ}$ ranged from 0.581-0.682, 0.422-0.656 and 0.396-0.618 for analogue film, Visualix and VistaScan respectively. The sensitivity and specificity of each observer group in relation to angle $+20^{\circ}$ are shown in Table 2. Using the Bonferroni modification following a significant ANOVA, a significant difference in the AUC was found between endodontists and GDPs, and endodontists and postgraduates $(p<0.05)$ for all three systems. However, there was no significant difference between the GDPs and postgraduates during the three interpretation sessions $(p>0.05)$ for any of the three systems.

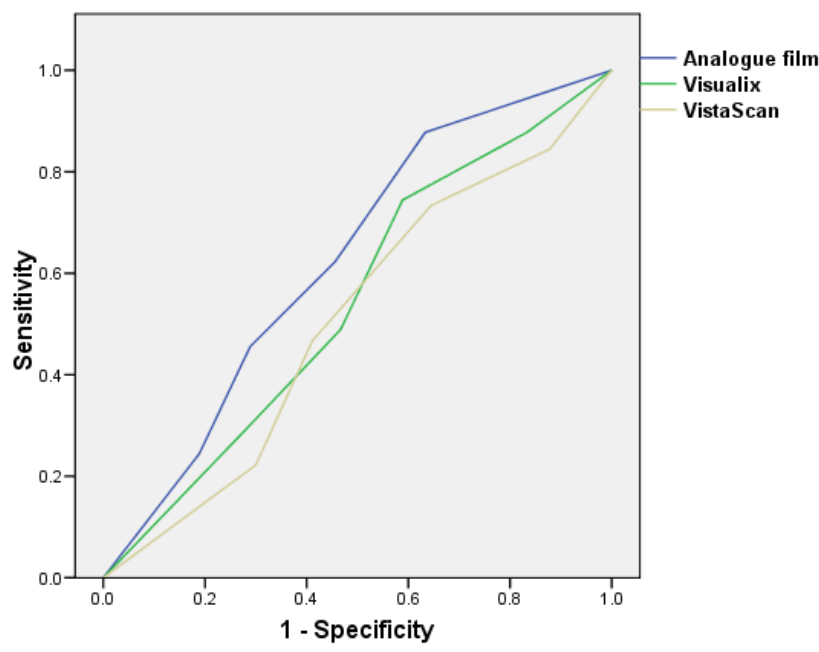

Figure 2. The ROC curve for all imaging modalities for angle $+20^{\circ}$

Table 1. Bonferroni post -hoc test results for all imaging modalities (Analogue film, Visualix and VistaScan)

\begin{tabular}{|c|c|c|c|}
\hline \multirow{2}{*}{ Analogue film } & Mean difference(SE) & 95\% confidence intervals \\
\cline { 2 - 4 } & Visualix & $-0.389 *(0.15)$ & -0.750 to -0.028 \\
\hline \multirow{2}{*}{ Visualix } & VistaScan & $-0.367 *(0.15)$ & -0.728 to -0.005 \\
\cline { 2 - 4 } & Analogue film & $0.389 *(0.15)$ & 0.028 to 0.750 \\
\hline \multirow{2}{*}{ VistaScan } & VistaScan & $0.022(0.15)$ & -0.339 to 0.383 \\
\cline { 2 - 4 } & Analogue film & $0.367 *(0.15)$ & 0.005 to 0.728 \\
\hline
\end{tabular}

* The mean difference is significant at the 0.05 level

Table 2. The sensitivity and specificity of each observer groups in relation to angle $+20^{\circ}$

\begin{tabular}{|c|c|c|c|c|}
\hline System & Test & Endodontists (\%) & GDPs (\%) & Postgraduates (\%) \\
\hline \multirow{2}{*}{ Analogue } & sensitivity & 53 & 53 & 47 \\
\hline & specificity & 80 & 57 & 57 \\
\hline \multirow{2}{*}{ Visualix } & sensitivity & 50 & 50 & 37 \\
\hline & specificity & 77 & 53 & 40 \\
\hline \multirow{2}{*}{ Vistascan } & sensitivity & 50 & 50 & 40 \\
\hline & specificity & 73 & 40 & 37 \\
\hline
\end{tabular}




\section{Discussion}

The ability of the observer to identify the presence of MB2 canal of maxillary molars is currently dependant on intraoral radiography. In recent years, the development of MCT has acquired an increasing significance in the study of tooth structures [13, 14] allowing a clear visualisation of the three-dimensional root canal morphology without sample destruction.

The determination of the presence or absence of anatomical features by radiographic examination is dependent on many factors. The latter includes radiographic density, sharpness, contrast and image resolution [15]. Within the current study, the methodology adopted ensured that each of the radiographs viewed by the observers showed optimal geometry whilst those acquired using conventional processing techniques provided optimal density and contrast. Additionally, the use of a protractor ensured reproducibility of beam alignment. For those images produced using digital sensors, the image viewed was one which displayed optimised density and contrast. Each of these images was viewed using ideal viewing conditions, leaving the image receptor as the only variable. Comparable findings to the current study have been produced by previous researchers [16].

The ability to visualise structural details and, therefore, to perform a precise diagnostic task with an imaging system is largely dependent on the signal-to-noise ratio $[17,18]$. Contrast and spatial resolution fundamentally defines the limits of perceptibility and accuracy within the image [19, 20]. The latter are considered an important aid to the radiographic perception of small and low contrast objects within the anatomy of the root canal. It has been shown that higher film resolution and, concomitantly, a higher signal-to-noise ratio results in improved visualisation of root canal morphology [11]. Farman and Farman have previously reported that $\mathrm{F}$-speed film has a spatial resolution exceeding 201p/mm [21], whilst the corresponding resolution for PSP was around $191 \mathrm{p} / \mathrm{mm}$ [22] and for Visualix was $11.41 \mathrm{p} / \mathrm{mm}$ [23]. The findings of the present study are in agreement with those of Farman and Farman [21].

Whilst there are undoubtedly similarities in the nominal spatial resolution of both PSP sensors and analogue film, Ramamurthy et al. [11] have found that from the standpoint of the observer there are significant differences between the two imaging systems. The researchers concluded that the reasons for these differences might be due to the radiation-detecting capability of the system as well as the display configuration of the system which may limit the imaging of small and low-contrast objects such as the MB2 canal. In the current study, the observers were not allowed to use image enhancement. It was believed that by fixing the image display setting, each clinician was offered an equal chance of comparable performance to those observers who were less experienced with subjective manipulation of digital format images. Moreover, by adopting this stance, the duration of the interpretation session was shortened thereby concurrently reducing the possibility of observer fatigue [24]. Additionally, it has been shown that the incorrect use of image enhancement may result in a decrease in the diagnostic performance of the observer [25]. It was noticeable that the observers performed better during the interpretation session of analogue films than was the case when the digital films were viewed. The latter was probably due to the observers having more clinical experience of assessing analogue films than was the case for digital radiography which had only recently been introduced into the hospital in which this study was conducted. Moreover, other factors such as the lower luminance of the monitor utilised to display the digital images than that of the viewing box might have played a part in the difference in the results obtained between analogue and digital images [24,26]. The deliberate modification of the horizontal beam angulation may provide further information for the clinician from the diagnostic radiograph. Research has shown that the angulation lies somewhere between $20^{\circ}$ and $40^{\circ}$ for the identification of two canals within one root [12,27,28]. When the observers' responses were analysed independently for each angle using ROC analysis, the largest AUC values were at the horizontal beam angulation of $20^{\circ}$ right followed by $20^{\circ}$ left to the maxillary first molar for each of the three imaging modalities. This finding is in accordance with other researchers whom concluded that a $20^{\circ}$ horizontal beam angulation in a direction right to a maxillary premolar allowed identification of possible superimposed root canals of this tooth [28, 29]. Barton et al. [10] reported that by using $20^{\circ}$ horizontal angulation there was less than a $40 \%$ chance of locating MB2 canals in the MB root of maxillary first molar by using parallax with pairs of digital or analogue radiographs. This percentage relates to the findings of the current study in which MB2 canals were successfully located in less than $50 \%$ of teeth when using either analogue or digital radiography. Conversely, the current study found that with a $30^{\circ}$ horizontal beam angulation, the observers' ability to identify the presence or absence of the MB2 canal became compromised due to overlapping and root superimposition from the maxillary first and second permanent molars.

The three groups of observers with different clinical backgrounds were chosen for this study because it was hypothesised that the clinical experience and level of training of the observers might be an important factor in their abilities to correctly identify MB2. Unsurprisingly, endodontists were found to have a higher sensitivity and specificity than GDPs and the postgraduate students. This has been confirmed by several studies $[30,31]$.

\section{Conclusions}

A $+20^{\circ}$ horizontal beam angulation was found to be optimal in the identification of MB2 canal of the maxillary first molar when using analogue film, Visualix or VistaScan. 
In addition, analogue film was found to be superior to either digital system. Observer experience was found to be an influential factor in the accurate detection of MB2 canal.

\section{REFERENCES}

[1] Vertucci F. Root canal morphology and its relationship to endodontic procedure. Endod Topics 2005;10: 3-29,

[2] Cohen S, Hargreaves M. Pathways of the pulp. $9^{\text {th }}$ ed. 2006; St. Louis, MO: Mosby Elsevier.

[3] Cleghorn BM, Christie WH, Dong CC. Root and root canal morphology of the human permanent maxillary first molar: a literature review. J Endod 2006; 32:813-821.

[4] Hartwell G, Bellizzi R. Clinical investigation of in vivo endodontically treated mandibular and maxillary molars. J Endod1982; 8: 555-557.

[5] Kulild JC, Peters DD. Incidence and configuration of canal systems in the mesiobuccal root of maxillary first and second molars. J Endod1990;16: 311-317.

[6] Tachibana H, Matsumoto K. Applicability of X-ray computerized tomography in endodontics. Endod Dent Traumatol $1990 ; 6: 16-20$.

[7] Nielsen RB, Alyassin AM, Peters DD, Carnes DL, Lancaster J. Microcomputed tomography: an advanced system for detailed endodontic research. J Endod 1995; 21:561- 568.

[8] Plotino G, Grande NM, Pecci R, Bedini R, Pameijer CH, SOMMA F. Three-dimensional imaging using microcomputed tomography for studying tooth macromorphology. J Am Dent Assoc 2006;137: 1555-1561.

[9] Nance R, Tyndall D, Levin LG, Trope M. Identification of root canals in molars by tuned-aperture computed tomography. Int Endod J 2000; 33: 392-396.

[10] Barton DJ, Clark SJ, Eleazer PD, Scheetz JP, Farman AG. Tuned-aperture computed tomography versus parallax analog and digital radiographic images in detecting second mesiobuccal canals in maxillary first molars. Oral Surg Oral Med Oral Pathol Oral Radiol Endod 2003; 96: 223-328.

[11] Ramamurthy R, Scheetz JP, Clark SJ, Farman AG. Effects of imaging system and exposure on accurate detection of the second mesio-buccal canal in maxillary molar teeth. Oral Surg Oral Med Oral Pathol Oral Radiol Endod 2006;102: 796-802.

[12] Klein RM, Blake SA, Nattress BR, Hirschmann PN. Evaluation of X-ray beam angulation for successful twin canal identification in mandibular incisors. Int Endod J 1997;30: 58-63.

[13] Somma F, Leoni D, Plotino G, Grande NM, Plasschaert A. Root canal morphology of the mesiobuccal root of maxillary first molars: a micro-computed tomographic analysis. Int Endod J 2009;42: 165-174.

[14] Park JW, Lee JK, Ha BH, Choi JH, Perinpanayagam H. Three-dimensional analysis of maxillary first molar mesiobuccal root canal configuration and curvature using micro-computed tomography. Oral Surg Oral Med Oral Pathol
Oral Radiol Endod 2009;108:437-442.

[15] White SC, Pharoah MJ. Oral radiology: principles and interpretation. $4^{\text {th }}$ ed 2000;St. Louis: Mosby.

[16] Naoum HJ, Chandler NP, Love R M. Conventional versus storage phosphor-plate digital images to visualize the root canal system contrasted with a radiopaque medium. J Endod 2003;29:349-352.

[17] Hayakawa Y, Farman AG, Kelly MS, Kuroyanagi K. Intraoral radiographic storage phosphor image mean pixel values and signal-to-noise ratio: effects of calibration. Oral Surg Oral Med Oral Pathol Oral Radiol Endod 1998; 86: 601-605.

[18] Kitagawa H, Farman AG. Effect of beam energy and filtration on the signal-to-noise ratio of the Dexis intraoral X-ray detector. Dentomaxillofac Radiol 2004;33: 21-24.

[19] Motz JW, Danos M. Image information content and patient exposure. Med Phys 1978; 5: 8-22.

[20] Chotas HG, Floyd, CE JR, Dobbins JT, Ravin CE. Digital chest radiography with photostimulable storage phosphors: signal-to-noise ratio as a function of kilovoltage with matched exposure risk. Radiology 1993;186: 395-398.

[21] Farman TT, Farman AG. Evaluation of a new F speed dental $\mathrm{X}$-ray film. The effect of processing solutions and a comparison with D and E speed films. Dentomaxillofac Radiol 2000;29: 41-45.

[22] Vistascan Perio User and installation manual VistaScan Perio (2007).

[23] Visualix USB. User and installation manual Visualix USB (2004).

[24] Yalcinkaya S, Kunzel A, Willers R, Thoms M, Becker J. Subjective image quality of digitally filtered radiographs acquired by the Durr Vistascan system compared with conventional radiographs. Oral Surg Oral Med Oral Pathol Oral Radiol Endod 2006;101: 643-651,

[25] Tyndall DA, Ludlow, JB, Platin E, Nair M. A comparison of Kodak Ektaspeed Plus film and the Siemens Sidexis digital imaging system for caries detection using receiver operating characteristic analysis. Oral Surg Oral Med Oral Pathol Oral Radiol Endod 1998; 85: 113-118.

[26] Kundel HL. Visual perception and image display terminals. Radiol Clin North Am 1986; 24: 69-78.

[27] Walton RE. Endodontic radiographic technics. Dent Radiogr Photogr 1973; 46: 51-59.

[28] Martinez-Lozano MA, Forner-Navarro L, Sanchez-Cortes JL. Analysis of radiologic factors in determining premolar root canal systems. Oral Surg Oral Med Oral Pathol Oral Radiol Endod 1999;88: 719-722.

[29] Mcdonald NJ, Hovland EJ. Surgical endodontics. In Walton R $\&$ Torabinejad M (Eds.) Principles and practice of endodontics. 1996; 2nd ed. Philadelphia: WB Saunders.

[30] Corcoran J, Apicella MJ, Mines P. The effect of operator experience in locating additional canals in maxillary molars. $\mathrm{J}$ Endod 2007;33: 15-17.

[31] Iqbal M, Fillmore E. Preoperative predictors of number of root canals clinically detected in maxillary molars: a PennEndo Database study. J Endod 2008;34:413-416. 